\title{
Genotoxicidad de tres plaguicidas utilizados en la actividad bananera de Costa Rica
}

\author{
Rebeca Vindas ${ }^{1}$, Fernando Ortiz ${ }^{1}$, Vanessa Ramírez ${ }^{1,3} \&$ Patricia Cuenca $^{1,2}$ \\ 1 Instituto de Investigaciones en Salud (INISA), Universidad de Costa Rica. 2060 San José, Costa Rica. \\ 2 Escuela de Biología. Universidad de Costa Rica. 2060 San José, Costa Rica. \\ 3 Escuela de Nutrición. Universidad de Costa Rica. 2060 San José, Costa Rica. \\ Correspondencia: Patricia Cuenca, INISA, Universidad de Costa Rica, 2060 San José, Costa Rica. Tel: 506 (2243668), \\ Fax: (506) 207 5130; pcuenca@ cariari.ucr.ac.cr
}

Recibido 18-II-2004. Corregido 23-VII-2004. Aceptado 24-VIII-2004.

\begin{abstract}
Genotoxicity of three pesticides used in Costa Rican banana plantations. The in vitro genotoxicity of imazalil and thiabendazole fungicides and the insecticide chlorpyrifos, compounds used in Costa Rican banana plantations, was evaluated with the single-cell gel electrophoresis technique (comet assay). The comet assay is a simple, rapid and low cost technique for quantification of DNA damage. This assay detects DNA single-strand breaks and alkali-labile sites in individual cells. The effects were analyzed by using human lymphocytes exposed to doses of $0,25,50,75$ and $100 \mathrm{~g} / \mathrm{ml}$ of each pesticide for $30 \mathrm{~min}$ at $37^{\circ} \mathrm{C}$. The cells were embedded in agarose, lysed, subjected to alkaline electrophoresis $(\mathrm{pH}>13)$ for $20 \mathrm{~min}$ at $25 \mathrm{~V}$, neutralized and dehydrated to be stained with a fluorescent dye and later comets visualization with the epifluorescence microscope. Chlorpyrifos and imazalil induced significant DNA damage in a dose-dependent manner. Chlorpyrifos was the major inductor of DNA breaks. These results indicate that both are genotoxic compounds in vitro. Thiabendazole fungicide did not induced DNA damage using the comet assay for all concentrations tested. Rev. Biol. Trop. 52(3): 601-609. Epub 2004 Dic 15.
\end{abstract}

Key words: Single-cell gel electrophoresis, comet assay, imazalil, chlorpyrifos, thiabendazole, lymphocytes, genotoxic.

Palabras clave: Electroforesis de células únicas, ensayo cometa, imazalil, clorpirifos, tiabendazol, linfocitos, genotóxico.

La necesidad de producir una mayor cantidad y calidad de alimentos mediante el control de plagas trajo como consecuencia el uso intensivo de los plaguicidas durante los últimos 50 años (García 1997, Chaverri et al. 2000). El uso creciente y la inadecuada manipulación de estas sustancias han despertado inquietudes sobre los riesgos y daños que podrían provocar en la economía, el ambiente y la salud pública (Anónimo 1986, Jiménez 1995). Los plaguicidas representan problemas de intoxicación para las personas que manipulan, aplican o trabajan con estos productos. De acuerdo al tipo de toxicidad, estas sustancias afectan el crecimiento y la sobrevivencia por factores reproductivos, y en el caso de toxicidad aguda podrían causar la muerte de los organismos expuestos (Baradon y Frixione 1982, Campbell 1987). También se les ha relacionado a largo plazo con carcinogénesis, mutagénesis, efectos reproductivos y hormonales, entre otros. Los agroquímicos capaces de inducir cambios en el material genético de tejido somático y germinal son considerados mutagénicos, ya que contribuyen a la aparición de malformaciones congénitas y a la etiología del cáncer (Hilje et al. 1987, Wesseling 1993, 1997). Estudios epidemiológicos los han asociado con cáncer gástrico, de piel, riñones, hígado, próstata, testículos en individuos 
expuestos; además de sarcomas, leucemia, linfoma de no-Hodgkin, mielomas y otros (Wesseling 1997).

Desde 1992 Costa Rica es el país de América Latina con mayor consumo de plaguicidas, por hectárea y por trabajador (Sanz-Bustillo et al. 1997). En 1993 se estimó que el consumo de plaguicida era de $2 \mathrm{~kg}$ de ingrediente activo por costarricense, $22 \mathrm{~kg}$ por trabajador agrícola y $64 \mathrm{~kg}$ por trabajador de las bananeras (Wesseling 1997). Los trabajadores de la industria bananera tienen un alto riesgo de sufrir intoxicaciones como consecuencia de exposiciones a plaguicidas, principalmente al plaguicida paraquat y a los inhibidores de la colinesterasa con consecuencias neurotóxicas y riesgo de cáncer a largo plazo (Wesseling 1997). En 1979, el uso del nematicida dibromocloropropano (DBCP) fue suspendido luego de comprobarse la esterilización y reducción del número de espermatozoides de 1500 trabajadores de compañías bananeras (Jiménez 1995, Wesseling 1996).

Estudios sobre el efecto genotóxico de la exposición ocupacional en trabajadoras de las plantas empacadoras de banano mostraron que las mujeres expuestas a plaguicidas presentaban un aumento significativo de fracturas cromosómicas y un mayor daño en la hebra sencilla del ADN, en comparación con las mujeres no expuestas. El daño detectado en el ADN fue mayor en las mujeres que tienen entre cinco y quince años de laborar en las empacadoras. Las trabajadoras del empaque del banano están expuestas directamente al tiabendazol y al imazalil, que se utilizan dentro de la planta empacadora, y al insecticida clorpirifos que viene impregnado en las bolsas que protegen los racimos de la fruta (Cuenca et al.1997, Ramírez 1998, Ramírez y Cuenca 2002).

Las lesiones en el material genético pueden aumentar el riesgo de padecer cáncer, de tener problemas reproductivos y otras afecciones, de ahí que el uso de biomarcadores es útil para detectar el daño genotóxico (Ramírez y Cuenca 2002, Castro et al. 2004, Cuenca y Ramírez 2004).
La técnica de electroforesis de células únicas o ensayo cometa es una de las pruebas capaces de detectar daños en el ADN y que es aplicable a estudios de biomonitoreo (Lebailly et al. 1997). Se caracteriza por ser un método sensible, rápido, sencillo, de bajo costo y aplicable a varios tipos de células (MckelveyMartin et al. 1993). La versión de Singh et al. (1988) bajo condiciones de lisis y electroforesis alcalina $(\mathrm{pH}>13)$ permite analizar la migración del ADN debido a rupturas en la hebra simple del ADN y sitios álcali-lábiles (Speit y Hartmann 1999). El ensayo cometa se utiliza ampliamente para detectar en células individuales, el daño in vitro o in vivo causado al ADN por agentes genotóxicos, ya sean químicos o físicos (Fairbairn et al. 1995, Rojas et al. 1999, Tice et al. 2000).

La técnica ha sido utilizada principalmente para el estudio del daño genético inducido por plaguicidas, mutágenos ambientales, nitrosaminas, drogas y fumado, entre otros (Betti et al. 1994, Fairbairn et al. 1995, Rojas et al. 1999). Por otra parte, con algunas modificaciones pueden evaluarse la inducción de enlaces cruzados, los mecanismos de reparación celular y de apoptosis (Fairbairn et al. 1995, Speit y Hartmann 1999, Tice et al. 2000).

En el presente trabajo se utilizó el ensayo cometa para evaluar la genotoxicidad in vitro de tres plaguicidas utilizados en las industria bananera de Costa Rica, con el fin de obtener información sobre cuál o cuales de las tres sustancias podrían contribuir al daño en el ADN encontrado en estudios anteriores (Cuenca et al.1997, Ramírez 1998, Ramírez y Cuenca 2002).

\section{MATERIALES Y MÉTODOS}

Agentes químicos: se evaluó el efecto del insecticida clorpirifos (Dursbán) [O,O dietilo(3,5,6-tricloro-2-pirinil) fosforotioato] C.A.S \#2921-88-2 (22.5\% i.a) y de los fungicidas imazalil [ $\pm 1-(2-(2,4$ diclorofenil)-2-(2-propeniloxi etil)-1H-imidazol] C.A.S \#35554-44-0 (75\% i.a) y el tiabendazol [2-(4-tiazolil) 
benzimidazol] C.A.S. \#148-79-8 (22\% i.a), en formulaciones comerciales. El clorpirifos se encuentra impregnado en las bolsas que protegen los racimos de banano, el imazalil y el tiabendazol son usados como fungicidas poscosecha.

Preparación de las células: las células blancas se aislaron de muestras de sangre de 6 donadores voluntarios (tres de cada sexo), sanos no fumadores, con una edad promedio de 24.5 años. Por cada individuo y tratamiento, se tomaron $10 \mathrm{ml}$ de sangre heparinizada que se procesó según el procedimiento desarrollado por Ramírez (1998), con algunas modificaciones.

Tratamiento in vitro de las células: se tomaron 601 de linfocitos por tratamiento y se expusieron a soluciones de $0,25,50,75$ y 100 $\mathrm{g} / \mathrm{ml}$ de cada uno de los plaguicidas por 30 min a $37^{\circ} \mathrm{C}$. La concentración de $0 \mathrm{~g} / \mathrm{ml}$ se empleó como control negativo y se utilizó el agua oxigenada $\left(\mathrm{H}_{2} \mathrm{O}_{2}\right)$ como control positivo a una concentración de $40 \mathrm{~g} / \mathrm{ml}$ (McKelveyMartin et al. 1993, Tice 1995).

Electroforesis de células únicas: se realizó mediante la técnica implementada por Singh et al. (1988) y Lebailly et al. (1997), con las modificaciones hechas por Ramírez (1998). Se prepararon dos repeticiones por cada tratamiento. Una vez terminado el procedimiento, se deshidrataron los portaobjetos con etanol absoluto por 5 min para permitir la conservación de los mismos hasta su respectiva visualización.

Análisis microscópico: las preparaciones se tiñeron con 3001 de bisbenzimida (70 $\mathrm{g} / \mathrm{ml}$ ) (Sigma H33258) y se observaron en un microscopio de epifluorescencia (Leitz DIAPLAN). Por cada portaobjetos se tomaron fotografías a 15 células al azar con el lente de $25 \mathrm{X}$, usando una cámara (WILD MPS46/52) acoplada al microscopio. Se usó película en blanco y negro Ilford de $35 \mathrm{~mm}$ y ASA 400. La migración del ADN se determinó tomando la medida de la longitud del cometa en m, en los negativos fotográficos, aumentados 80 veces. Las células altamente dañadas con cabezas poco densas y colas muy largas o con apariencia de nube se excluyeron del análisis por considerarse células apoptóticas o muertas (Fairbairn et al. 1995).
Análisis estadístico: se utilizó la prueba tstudent para evaluar la genotoxicidad de los plaguicidas mediante incrementos significativos en la migración del ADN o longitud del cometa respecto al control negativo. Para determinar si existe una relación entre la concentración y el daño observado se usó el análisis de regresión lineal simple. Para este análisis se utilizó, para cada plaguicida, la migración promedio total de ADN por concentración (Gutiérrez 1995).

\section{RESULTADOS}

El imazalil y el clorpirifos causaron daño en la hebra sencilla del ADN, siendo el clorpirifos el que induce mayor daño genotóxico. El tiabendazol no provocó daños estadísticamente significativos en las concentraciones estudiadas en comparación con el control negativo ( $p<0.05$ ). Las concentraciones de 25, 50, $75 \mathrm{y}$ $100 \mathrm{~g} / \mathrm{ml}$, tanto del imazalil como del clorpirifos causaron incrementos altamente significativos $(p<0.0001)$ en la migración del ADN, con respecto al control negativo. El daño causado es dependiente de las concentraciones utilizadas (Cuadro 1).

La concentración más baja de imazalil duplicó la longitud de los cometas y la concentración de $75 \mathrm{~g} / \mathrm{ml}$ la triplicó con respecto a las células sin tratamiento. En la concentración de $100 \mathrm{~g} / \mathrm{ml}$ la migración de ADN disminuyó respecto al tratamiento de $75 \mathrm{~g} / \mathrm{ml}$. El clorpirifos provocó una mayor dispersión del ADN. En la concentración de $25 \mathrm{~g} / \mathrm{ml}$ la longitud del cometa aumentó 2.2 veces y en la concentración mayor el incremento fue de casi 4 veces, en contraste con el control negativo (Cuadro 1).

Existe una correlación lineal positiva entre la migración del ADN y las concentraciones probadas, tanto en el imazalil $(\mathrm{r}=0.92)$ como en el clorpirifos ( $\mathrm{r}=0.95)(p<0.05)$; no así para el tiabendazol $(\mathrm{r}=0.44)$, que no induce cambios en la migración del ADN al variar la concentración (Cuadro 2, Fig. 1). De este modo, conforme aumenta la concentración, la 


\begin{tabular}{|c|c|c|c|}
\hline \multicolumn{4}{|c|}{$\begin{array}{l}\text { Longitud del cometa en } m \text { de linfocitos de sangre periférica expuestos a distintos tratamientos con } \\
\text { los fungicidas imazalil y tiabendazol, y el insecticida clorpirifos }(n=180 \text { células/ tratamiento })\end{array}$} \\
\hline \multirow{2}{*}{\multicolumn{4}{|c|}{$\begin{array}{c}\text { TABLE } 1 \\
\text { Comet length }(\mathrm{m}) \text { of peripheral blood lymphocytes exposed to different treatments of pesticides: } \\
\text { imazalil, thiabendazole and chlorpyrifos }(n=180 \text { cells/ treatment })\end{array}$}} \\
\hline & & & \\
\hline \multirow[t]{2}{*}{ Concentración ( $\mathrm{g} / \mathrm{ml})$} & \multicolumn{3}{|c|}{ Longitud promedio del cometa ( $\mathrm{m})$} \\
\hline & Imazalil & Clorpirifos & Tiabendazol \\
\hline 0 & 15.08 & 15.47 & 18.39 \\
\hline 25 & $28.54^{\mathrm{a}}$ & $35.39^{\mathrm{b}}$ & 18.90 \\
\hline 50 & $37.37^{\mathrm{a}}$ & $40.92^{\mathrm{b}}$ & 18.88 \\
\hline 75 & $44.31^{\mathrm{a}}$ & $46.38^{\mathrm{b}}$ & 18.39 \\
\hline 100 & $41.52^{\mathrm{a}}$ & $53.38^{\mathrm{b}}$ & 18.20 \\
\hline
\end{tabular}

a y b: Diferencias significativas con el control negativo correspondiente $\mathrm{p}<0.0001$ con la prueba t-student.

CUADRO 2

Daño en la hebra simple del ADN. Regresión lineal simple para el análisis de la variable concentración

TABLE 2

Single stranded DNA damage. Simple linear regression for the analysis of the concentration variable

$\begin{array}{lccccc}\text { Plaguicida } & \text { Variable } & \begin{array}{c}\text { Coeficiente de } \\ \text { correlación }(\mathrm{r})\end{array} & \begin{array}{c}\text { Coeficiente de } \\ \text { determinación }\left(\mathrm{R}^{2}\right)\end{array} & \begin{array}{c}\text { Coeficiente de } \\ \text { regresión (b) }\end{array} & \begin{array}{c}\text { Significancia } \\ \text { (t-student) }\end{array} \\ \text { Imazalil } & \text { Concentración } & 0.91 & 0.84 & 0.27460 & 0.028 \\ \text { Clorpirifos } & \text { Concentración } & 0.95 & 0.91 & 0.34724 & 0.012 \\ \text { Tiabendazol } & \text { Concentración } & 0.44 & 0.20 & -0.00356 & 0.456\end{array}$

longitud del cometa también se incrementa. La variabilidad en la migración del ADN fue de un $84 \%$ y $91 \%$ para el imazalil y clorpirifos, respectivamente, como consecuencia de la exposición de los linfocitos a las concentraciones de los plaguicidas (Cuadro 2).

\section{DISCUSIÓN}

Los datos experimentales indican que el imazalil y el clorpirifos son compuestos con actividad genotóxica in vitro detectada con el ensayo cometa.

La genotoxicidad del imazalil no ha sido estudiada in vitro en células humanas; sin embargo, Muto et al. (1997) y Sanderson et al. (2002) demostraron la capacidad de este compuesto para inhibir la actividad del citocromo P450 dependiente de monoxigenasas en ratones
ddY y la enzima aromatasa CYP19 en células humanas. La enzima CYP19 es importante en la síntesis de esteroides por lo que el imazalil podría afectar el sistema reproductivo.

El clorpirifos es uno de los insecticidas de mayor uso en el mundo, de ahí que los posibles efectos de su exposición hayan sido ampliamente estudiados. Varios autores informaron que esta sustancia causa daño genético in vivo e in vitro porque mostró resultados positivos al evaluarla con diferentes sistemas, como los ensayos de aberraciones cromosómicas, de micronúcleos, de mutagénesis e incluso con el ensayo cometa. Sin embargo, su potencial mutagénico y carcinogénico continúa siendo controversial (Stachetti et al. 1998, Rahman et al. 2002).

A diferencia del imazalil y el clorpirifos, el tiabendazol no indujo daño al ADN en las concentraciones estudiadas. Lo anterior concuerda con otras investigaciones que tampoco 

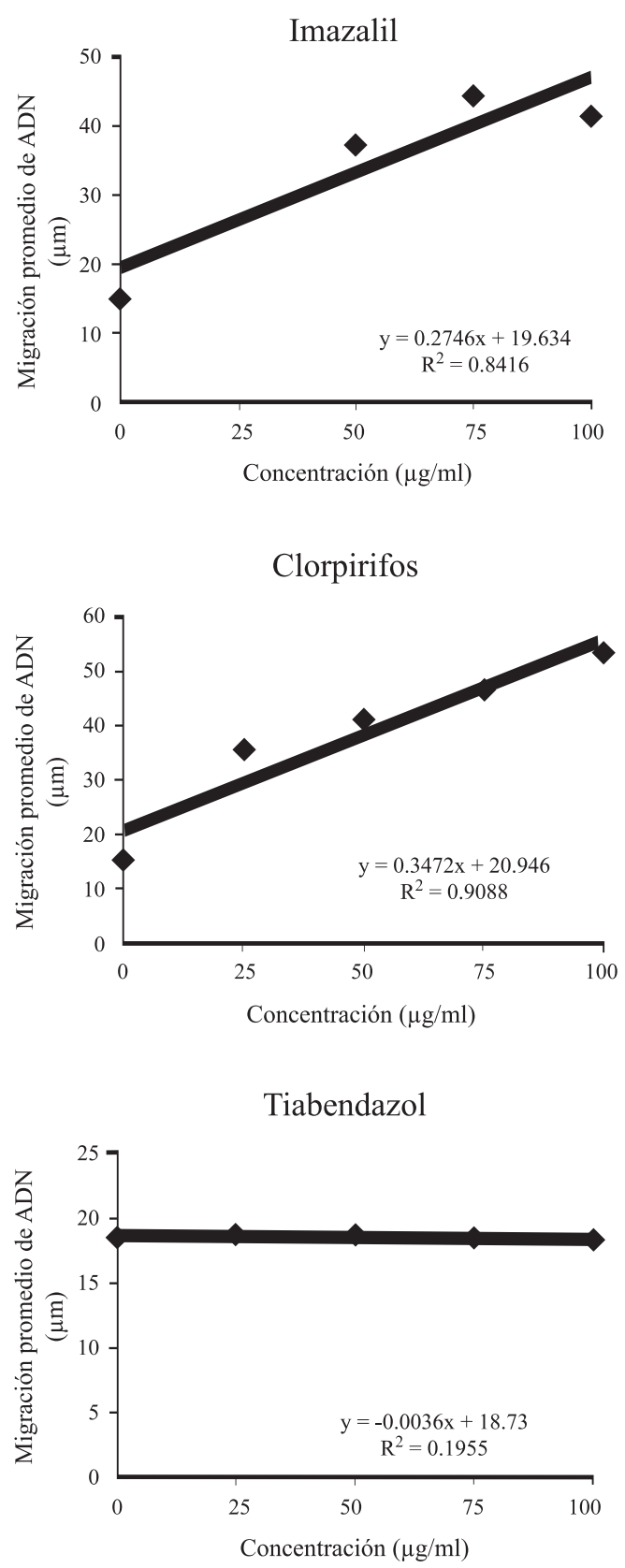

Fig. 1. Relación dosis-respuesta observada después de tratar linfocitos a diferentes concentraciones de los tres plaguicidas.

Fig. 1. Dose-response relationship observed after treating lymphocytes with three different pesticides. observaron efecto genotóxico del tiabendazol en ensayos in vivo e in vitro de aberraciones cromosómicas y con los estudios de mutagenicidad y carcinogénesis en ratones, conejos y bacterias (Lankas et al. 2001, Tada et al. 2001, Watanabe-Akanuma et al. 2003). Además, el tiabendazol presenta una débil actividad aneugénica en células somáticas y germinales que es característica de los compuestos químicos relacionados al benzimidazol (Mailhes et al. 1997). Watanabe-Akanuma et al. (2003) no observaron efectos mutagénicos en bacterias expuestas a tiabendazol. Sin embargo, informaron sobre su capacidad mutagénica cuando es fotoactivado con luz UV. El ensayo cometa se ha utilizado en estudios in vivo con ratones ddY y CD-1, a los que se les suministraron dosis orales de tiabendazol $(200-2000 \mathrm{mg} / \mathrm{kg}$ ) para determinar el daño al ADN en varios órganos como el estómago, hígado, pulmón, entre otros, y se encontraron incrementos significativos en la longitud del cometa (Sasaki et al. 1997, 2002). Sin embargo, la técnica no ha sido empleada para evaluar el efecto genotóxico del tiabendazol en células humanas.

Las rupturas que se producen en el ADN pueden ser producto de: (a) La acción directa de una sustancia genotóxica en el material genético, (b) La activación de mecanismos de reparación en las células y (c) Los procesos normales de apoptosis, necrosis y duplicación celular. La técnica permite medir eficazmente las lesiones como producto de la interacción directa de los plaguicidas con el ADN, porque el tiempo entre la exposición y la expresión del daño es muy corto cómo para desencadenar los procesos de reparación celular (Ribas et al. 1995). Algunos autores afirman que las fracturas del ADN formadas mientras actúan los mecanismos de reparación por escisión de bases, también causan migración del ADN, cuantificable con el ensayo cometa, por lo que la reparación del ADN puede influir en los resultados obtenidos en los estudios in vivo (Hartmann et al. 1995 citado por Blasiak et al. 1999). Sin embargo, los mecanismos de reparación 
actúan si aparecen alteraciones en el material genético, como las inducidas por los plaguicidas genotóxicos.

Los cometas que se forman como producto de los procesos normales de la célula no interfieren, en este caso, con la interpretación de los datos obtenidos ya que los resultados se están comparando con el control negativo.

Para efectos de esta investigación la primera causa es la más relevante y consiste en la modificación química que sufre el $\mathrm{ADN}$ al reaccionar directamente con el imazalil y el clorpirifos. Se producen alteraciones en las bases nitrogenadas, ya sean aductos o sitios abásicos en la molécula. La mayoría de las sustancias consideradas genotóxicas y/o carcinogénicas son altamente electrofílicas, por sí solas; o pueden ser activadas a metabolitos electrofílicos por medio de los mecanismos del metabolismo xenobiótico de los seres vivos. Las sustancias electrofílicas tienen la capacidad de unirse covalentemente a moléculas biológicas (Searle 1984). En compuestos organofosforados como el clorpirifos, el grupo fosforilo es un sitio electrofílico potencial que puede reaccionar con el ADN y su grupo alquilo tiene la capacidad de interaccionar con centros nucleofílicos de la molécula como el nitrógeno 7 de la guanina. En el caso del imazalil, probablemente el grupo etil (alquilo) y el anillo polar imidazole $\left(\mathrm{C}_{3} \mathrm{H}_{4} \mathrm{~N}_{2}\right)$ facilitan la acción de este plaguicida sobre el ADN. De este modo, el clorpirifos y el imazalil podrían estar actuando como agentes alquilantes (AA). Los AA pueden reaccionar con centros altamente nucleofílicos del ADN (átomos de nitrógeno) o poco nucleofílicos (átomos de oxígeno). La alquilación de los oxígenos está relacionada con efectos mutagénicos y oncogénicos, mientras que la de los nitrógenos se asocia con citotoxicidad. La polaridad del fosforilo (presente en el insecticida clorpirifos) y del anillo imidazole (en el fungicida imazalil) podría favorecer la unión de los plaguicidas al ADN, lo que lleva a la formación de aductos en la molécula que se traducen en rupturas cuando se realiza el ensayo cometa. La acción del clorpirifos sobre el ADN se caracteriza por la inhibición de la síntesis del ADN (Qiao et al. 2003). El tiabendazol no provoca daños genotóxicos significativos, debido a que no posee carbamatos del tipo benzimidazol; ni es metabolizado a este tipo de sustancias, a diferencia de otros compuestos químicamente similares como el benomil y el carbendazin (Lankas et al. 2001). Sin embargo, el tiabendazol inhibe el ensamblaje de los microtúbulos lo que explica su leve capacidad para provocar aneuploidías (Mailhes et al. 1997).

Los daños en el ADN producidos por efectos genotóxicos están relacionados con la inducción de mutaciones y subsecuentemente con la etiología del cáncer. Las células que sufren daños en el material genético pueden ser incapaces de reparar las lesiones provocadas en su ADN, ya sea por deficiencia en los mecanismos de reparación o por reparaciones erróneas o incompletas. La pérdida en la integridad del ADN podría expresarse y transmitirse a la descendencia celular; lo que puede aumentar el riesgo de padecer cáncer y la posibilidad de desarrollar inestabilidad genómica o envejecimiento celular. Un aspecto a tomar en cuenta es el sitio en el que ocurren las rupturas; algunos plaguicidas pueden actuar sobre genes supresores de tumores, en los proto-oncogenes y en los genes involucrados en los mecanismos de reparación (Blasiak et al. 1999).

El imazalil y el clorpirifos causaron daños en la hebra simple del ADN de manera dependiente en las concentraciones usadas, sin embargo, la linealidad positiva se perdió por el efecto citotóxico que podría presentarse en concentraciones altas, como en el caso del imazalil en la concentración de $100 \mathrm{~g} / \mathrm{ml}$.

La genotoxicidad in vitro del imazalil y el clorpirifos indica que estos plaguicidas probablemente contribuyeron al daño encontrado en el ADN de los linfocitos de las trabajadoras bananeras, observados por Ramírez y Cuenca (2002), y a una mayor frecuencia de fracturas cromosómicas observadas también en esta población (Cuenca et al. 1997). No obstante, estas trabajadoras están expuestas a mezclas complejas de plaguicidas, por lo que habría que analizar el comportamiento de las mezclas 
de ambos compuestos y de cada uno combinado con los otros plaguicidas usados en las plantaciones, para evaluar posibles efectos antagónicos o sinérgicos que modifiquen su potencial genotóxico. Por otra parte, en la vida real lo que se expone es el organismo completo, donde están activos los mecanismos de tolerancia, reparación y el metabolismo xenobiótico, efectuándose simultáneamente la acción conjunta de diversos órganos y hormonas que participan en la detoxificación, de tal modo que se debe tener mucha cautela al extrapolar los resultados que se obtienen en estudios in vitro a lo que ocurre in vivo (Betti et al. 1994, Ramírez 1998).

En los estudios de monitoreo genotóxico es fundamental contar con biomarcadores de gran sensibilidad y bajo costo que permitan aplicarse a muestras de diferente tamaño. La técnica de electroforesis de células únicas cumple con estos requisitos. Aunque es un método inespecífico, al igual que los ensayos de aberraciones cromosómicas y de micronúcleos, constituye una valiosa herramienta para estudiar el potencial genotóxico de agentes químicos o ambientales, por lo cual está siendo aplicada en gran cantidad de investigaciones.

\section{RESUMEN}

Se evaluó la genotoxicidad in vitro de los fungicidas imazalil y tiabendazol y del insecticida clorpirifos, formulaciones empleadas en las bananeras costarricenses, utilizando la técnica de electroforesis de células únicas (ensayo cometa). El ensayo cometa es una técnica simple, rápida y de bajo costo para la cuantificación de daños en el ADN, en términos de rupturas y sitios álcalilábiles, en la hebra simple del ADN de células individuales. Se expusieron linfocitos humanos a concentraciones de $0,25,50,75$ y $100 \mathrm{~g} / \mathrm{ml}$ de los plaguicidas, por $30 \mathrm{~min}$ a $37^{\circ} \mathrm{C}$. Las células fueron embebidas en agarosa, se provocó la lisis de sus membranas citoplasmáticas y se sometieron a electroforesis alcalina durante $20 \mathrm{~min}$ a $25 \mathrm{~V}$. Por último, las preparaciones se neutralizaron y se deshidrataron, para el posterior teñido de las láminas con el fluorocromo y la visualización de los cometas en el microscopio de epifluorescencia. El clorpirifos y el imazalil inducen daños significativos en la hebra sencilla del ADN en forma dependiente de la concentración, siendo el clorpirifos el mayor inductor de rupturas en el material genético. Estos resultados indican que ambos se comportan como compuestos genotóxicos in vitro. El fungicida tiabendazol mostró resultados negativos en las concentraciones empleadas.

\section{REFERENCIAS}

Anónimo. 1986. Clasificación de plaguicidas conforme a su peligrosidad. Centro Panamericano de Ecología Humana y Salud, México, D.F. 82 p.

Baradon, E. \& E. Frixione. 1982. Plaguicidas modernos y su acción bioquímica. Limusa, México D.F. 343 p.

Betti, C., T. Davini, L. Giannessi, N. Loprieno \& R. Barale. 1994. Microgel electrophoresis assay (comet test) and SCE analysis in human lymphocytes from 100 normal subjects. Mut. Res. 307: 323-333.

Blasiak, J., P. Jaloszynski, A. Trzeciak \& K. Szyfter. 1999. In vitro studies on the genotoxicity of the organophosphorus insecticide malathion and its two analogues. Mut. Res. 445: 275-283.

Campbell, R. 1987. Ecología Microbiana. Limusa, México D.F. 268 p.

Castro, R., V. Ramírez \& P. Cuenca. 2004. Análisis de micronúcleos y otras anormalidades nucleares en el epitelio oral de mujeres expuestas ocupacionalmente a plaguicidas. Rev. Biol. Trop. 52: 207-217.

Chaverri, F., L. Soto, F. Ramírez \& V. Bravo. 2000. Diagnóstico preliminar del uso de plaguicidas en los cultivos de arroz, banano, caña de azúcar, café, cebolla, melón, naranja, papa, piña, tomate, flores y plantas ornamentales. IRET, Universidad Nacional, Heredia, Costa Rica. 47 p.

Cuenca, P., V. Ramírez, R. Castro \& K. Schosinsky. 1997. Efecto genotóxico de los plaguicidas en una población ocupacionalmente expuesta. Evaluación por medio de micronúcleos de linfocitos y del epitelio bucal, aberraciones cromosómicas, mecanismos de reparación y electroforesis de células únicas, controlando paralelamente los niveles de colinesterasa sérica y eritrocítica. Proyecto PLAGSALUD/ MASICA, San José, Costa Rica. 62 p.

Cuenca, P. \& V. Ramírez. 2004. Aberraciones cromosómicas en trabajadoras expuestas a plaguicidas. Rev. Biol. Trop. 52: 219-224.

Fairbairn, D.W., P.L. Olive \& K.L. O’ Neill. 1995. The comet assay: a comprehensive review. Mut. Res. 339: 37-59.

García, J. 1997. Introducción a los plaguicidas. Universidad Estatal a Distancia, San José, Costa Rica. 450 p. 
Gutiérrez, E. 1995. Métodos estadísticos para las ciencias biológicas. EUNA, San José. 178 p.

Hilje, L., L. Castillo, L. Thrupp \& C. Wesseling. 1987. El uso de los plaguicidas en Costa Rica. Heliconia /UNED, San José, Costa Rica. 159 p.

Jiménez, J. 1995. Plaguicidas y salud en las bananeras de Costa Rica. Aseprola. San José, Costa Rica. 126 p.

Lankas, G.R., T. Nakatsuka, Y. Ban, T. Komatsu \& H. Matsumoto. 2001. Developmental toxicity of orally administered thiabendazole in ICR mice. Food. Chem. Toxicol. 39: 367-374.

Lebailly, P., C. Vigreux, T. Godard, F. Sichel, E. Bar, J.Y. Letalaër, M. Henry \& P. Gauduchon. 1997. Assesment of DNA damage induced in vitro by etoposide and two fungicides (carbendazim and chlorothalonil) in human lymphocytes with the comet assay. Mut. Res. 375: 205-217.

Mailhes, J.B., D. Young, M. Aardema \& S. London. 1997. Thiabendazole-induced cytogenetics abnormalities in mouse oocytes. Environm. Mol. Mut. 29: $367-$ 371.

Mckelvey-Martin, V.J., M.H.L. Green, P. Schmezer, B.L. Pool-Zobel, M.P. De Méo \& A. Collins. 1993. The single cell gel electrophoresis assay (comet assay): A European review. Mut. Res. 288: 47-63.

Muto, N., H. Hirai, T. Tanaka, N. Itoh \& K. Tanaka. 1997. Induction and inhibition of cytochrome P450 isoforms by imazalil, a food contaminant, in mouse small intestine and liver. Xenobiotica 27: 1215-1223.

Qiao, D., F. Seidler, J. Violin \& T. Slotkin. 2003. Nicotine is a developmental neurotoxicant and neuroprotectant: stage-selective inhibition of DNA synthesis coincident with shielding from effects of chlorpyrifos. Develop. Brain. Res. 147: 183-190.

Rahman, M., M. Mahboob, K. Danadevi, B. Banu \& P. Grover. 2002. Assessment of genotoxic effects of chloropyrifos and acephate by the comet assay in mice leucocytes. Mutat. Res. 516: 139-147.

Ramírez, V. 1998. Efecto genotóxico de los plaguicidas en una población costarricense de trabajadoras bananeras. Tesis de Magister Scientiae. en Biología, Universidad de Costa Rica, San José, Costa Rica. 107 p.

Ramírez, V. \& P. Cuenca. 2002. Daño del ADN en trabajadoras bananeras expuestas a plaguicidas en Limón, Costa Rica. Rev. Biol. Trop. 50: 507-518.

Ribas, G., G. Frenzilli, R. Barale \& R. Marcos. 1995. Herbicide-induced DNA damage in human lymphocytes evaluated by the single-cell gel electrophoresis (SCGE) assay. Mut. Res. 344: 41-54.

Rojas, E., M.C. López \& M. Valverde. 1999. Single cell gel electrophoresis assay: methodology and applications. J. Chromatogr B. 722: 225-254.

Sanderson, J.T., J. Boerma, G. Lansbergen \& M. van den Berg. 2002. Induction and inhibition of aromatase (CYP19) activity by various classes of pesticides in H295R human adrenocortical carcinoma cells. Toxicol. Appl. Pharmacol. 182: 44-54.

Sanz-Bustillo, J.J., L. Pratt \& J.M. Pérez. 1997. Uso de plaguicidas en la agroindustria de Costa Rica. Centro Latinoamericano de Competitividad y Desarrollo Sostenible del INCAE, Costa Rica. 62 p.

Sasaki, Y.F., A. Saga, M. Akasaka, K. Yoshida, E. Nishidate, Y.Q Su, N. Matsusaka \& S. Tsuda. 1997. In vivo genotoxicity of ortho-phenylphenol, biphenyl, and thiabendazole detected in multiple mouse organs by the alkaline single cell gel electrophoresis assay. Mut. Res. 395: 189-198.

Sasaki Y.F., S. Kawaguchi, A. Kamaya, M. Ohshita, K. Kabasawa, K. Iwama, K. Taniguchi \& S. Tsuda. 2002. The comet assay with 8 mouse organs: results with 39 currently used food additives. Mut. Res. 519: 103-119.

Searle, C. 1984. Chemical carcinogenesis. Amer. Chem. Soc. Monogr. 182 p.

Singh, N.P., M.T. McCoy, R.R. Tice \& E.L. Schneider. 1988. A single technique for quantitation of low levels of DNA damage in individual cells. Exp. Cell. Res. 175: 184-191.

Speit, G. \& A. Hartmann. 1999. The comet assay (Singlecell gel test): a sensitive genotoxicity test for detection of DNA damage and repair. Method. Mol. Biol. 113: 203-212.

Stachetti, G., D. Pimentel \& L. Weinstein. 1998. In situ assessment of pesticide genotoxicity in an integrated pest management program I- Tradescantia micronucleus assay. Mutat. Res. 412: 235-244.

Tada, Y., T. Fujitani, N. Yano, K. Yuzawa, A. Nagasawa, N. Aoki, A. Ogata \& M. Yoneyama. 2001. Chronic toxicity of thiabendazole (TBZ) in CD- 1 mice. Toxicology 169: 163- 176.

Tice, R.R. 1995. The single cell gel/ Comet assay: a microgel electrophoretic technique for the detection of DNA damage and repair individual cells. pp. 315339. In Phillips, D.H \& S. Venitt (eds.). Environmental Mutagenesis. Bios Scientific, Oxford, Inglaterra. 
Tice, R.R., E. Agurell, D. Andreson, B. Burlinson, A. Hartmann, H. Kobayashi, Y. Miyamae, E. Rojas, J.C. Ryu \& F. Sasaki. 2000. Single cell gel / Comet assay: Guidelines for in vitro and in vivo genetic toxicology testing. Environ. Mol. Mut. 35: 206-221.

Watanabe- Akanuma, M., T. Ohta \& H. Yamagata. 2003. Photomutagenicity of thiabendazole, a postharvest fungicide, in bacterial assays. Environm. Mol. Mut. 41: $92-98$.
Wesseling, C., L. Castillo \& C.G. Elinder. 1993. Pesticides poisonings in Costa Rica. Scand J. Environ Health. 19: $227-235$.

Wesseling, C., A. Ahlbom, D. Antich, A.C. Rodríguez \& R. Castro. 1996. Cancer in Banana Plantation Worker in Costa Rica. Int. J. Epidemiol. 25: 1125-1131.

Wesseling, C. 1997. Health effects from pesticide use in Costa Rica: an epidemiologic approach. Tesis Medicine Docktorsexamen, Karolinska Institutet, Estocolmo, Suecia. 308 p. 